\title{
Prevalência de Helicobacter em cães oriundos do biotério central da Universidade Estadual de São Paulo (UNESP)-Botucatu ${ }^{1}$
}

\author{
Prevalence of Helicobacter in canines from animal colony of the State University of \\ Sao Paulo (UNESP)-Botucatu
}

\author{
Maria Lúcia de Souza를 Shoiti Kobayasi ${ }^{3}$, Maria Aparecida Marchesan Rodrigues ${ }^{4}$, Rogério \\ Saad-Hossne ${ }^{5}$, Luiz Eduardo Naresse ${ }^{6}$
}
1.Trabalho desenvolvido na disciplina de Gastroenterologia Cirúrgica da Faculdade de Medicina - Universidade Estadual de São Paulo (FM-UNESP), Botucatu.
2.Pós-graduanda do Curso de Pós-Graduação, Bases Gerais da Cirurgia.
3.Professor Titular do Departamento de Cirurgia e Ortopedia da FM-UNESP, Botucatu.
4.Professora Adjunta do Departamento de Patologia da FM-UNESP, Botucatu.
5.Professor Doutor do Departamento de Cirurgia e Ortopedia da FM-UNESP, Botucatu.
6.Professor Adjunto do Departamento de Cirurgia e Ortopedia da FM-UNESP, Botucatu.

\begin{abstract}
RESUMO
OBJETIVO: Investigar a incidência de Helicobacter sp em cães oriundos do biotério central da UNESP.

MÉTODOS: Utilizamos 109 cães oriundos do Biotério Central da UNESP Campus de Botucatu verificando a presença do Helicobacter sp através do exame de histopatologia corado pelo método Giemsa, pelo teste rápido de urease (TRU) e a prevalência de Helicobacter pylori pelo teste sorológico imunocromatográfico.

RESULTADOS: O resultado para a presença de Helicobacter foi de 99\% pela histopatologia e pelo TRU e 78,8\% de prevalência para a espécie $H$. pylori pelo teste sorológico.

CONCLUSÃO: As formas encontradas pela microscopia de imersão foram contrárias ao resultado do teste sorológico, sendo visibilzado formas compatíveis com a espécie $H$. heilmannii na maioria das amostras, e uma segunda forma de Helicobacter com características morfológicas distintas do $H$. pylori encontrado em humanos.
\end{abstract}

DESCRITORES: Helicobacter. Gastrite. Cães.

\begin{abstract}
PURPOSE: To investigate the incidence of Helicobacter sp in dogs from the animal colony of UNESP. METHODS: One hundred and nine dogs from the animal colony of UNESP- Botucatu, SP were studied to verify the presence of Helicobacter sp. The methods used were: histopathology stained by Giemsa, rapid urease test (RUT) and the prevalence of Helicobacter pylori was tested by serologic immunocromatography.

RESULTS: The presence of Helicobacter was found in 99\% of the cases when using the histopathology and RUT methods. The prevalence of $H$. pylori tested by immunocromatography was of $78.8 \%$.

CONCLUSIONS: The forms found under microscopy oimmersion were contrary to the serologic test, where forms compatible to the $H$. heilmannii were found in the majority of the samples. A second form of Helicobacter with different morphologic characteristics from the human $H$. pylori was also found.
\end{abstract}

KEY WORDS: Helicobacter. Gastritis. Dogs. 


\section{Introdução}

Vários estudos no ser humano têm demonstrado a correlação do Helicobacter pylori $(\mathrm{Hp})$ na patogenia da gastrite, da úlcera gástrica e duodenal e mais recentemente como agente indutor do carcinoma gástrico no ser humano ${ }^{1}$. A associação com outras doenças, como trombocitopenia auto-imune, nefropatia membranosa, polineuropatias imunes agudas, doença cardíaca isquêmica, carcinoma hepático, colangite esclerosante primária e cirrose biliar primária e também em doença coronariana está sendo investigada (REF.)

É estimado que metade da população mundial esteja colonizada por este patógeno e que a maioria dela foi colonizada ainda na idade escolar², porém muitos indivíduos colonizados permanecem assintomáticos.

A infecção pela bactéria tem correlação inversa com o padrão socioeconômico e nos países em desenvolvimento como o Brasil, a colonização do estômago humano pelo Hp é disseminada ${ }^{3}$.

O estômago constitui reservatório habitual da bactéria, e suas características permitem que ela habite o muco que recobre o epitélio gástrico, levando danos à mucosa gástrica, conseguindo desta maneira sobreviver nesse ambiente por décadas.

A forma exata pela qual ocorre a transmissão desta Helicobacteriose é desconhecida, o isolamento de Hp em saliva, placa dentária e nas fezes reforça a hipótese de transmissão oro-oral ou oro-fecal.

Outras espécies de Helicobacter foram identificadas no ser humano, sendo que o Helicobacter heilmannii $(\mathrm{Hh})$ foi associado à gastrite $^{4}$ e ao linfoma MALT gástrico primário ${ }^{1}$. Nessa associação, a erradicação da bactéria resultou no desaparecimento do linfoma gástrico ${ }^{1}$; a infecção por Hh em seres humanos é bem menos freqüente do que a verificada com o $\mathrm{Hp}$, sendo possível a concomitância de infecção por ambas as espécies de bactérias ${ }^{4}$.

A avaliação histológica do estômago na espécie canina também mostrou a presença de bactérias espiraladas, mas com ocorrência predominante no corpo e fundo gástricos. A bactéria foi diagnosticada no muco, nas criptas gástricas, nas glândulas gástricas e nas células parietais, sendo que o diagnóstico de gastrite leve à moderada é achado freqüente em cães, tanto sadios quanto naqueles com sintomas de doença gástrica, independentemente do grau de colonização por estas bactérias ${ }^{5,6,7}$. Do mesmo modo, também não se observou alteração na função secretora gástrica entre cães colonizados ou não pelo Helicobacter ${ }^{11}$.

Desse modo, na espécie canina, ainda não se conseguiu evidências na correlação entre a presença da bactéria na mucosa gástrica e os sintomas digestivos apresentados por esses animais, à despeito de alta incidência de colonização pelo Helicobacter, sendo relatadas taxas entre $72 \%$ a $100 \% 0^{5,6,7,8,9,10}$. Estes estudos sugerem que o Helicobacter possa a ser um dos componentes normais da flora gástrica do cão.

As pesquisas relativas à incidência de Helicobacter em caninos foram realizados em animais sadios ou com doenças gástricas pertencentes à proprietários definidos ou de criadores de animais para laboratório, sendo que cães naturalmente infectados pelo Helicobacter pylori nunca foram documentados.

A presente investigação teve como objetivo o estudo da prevalência de Helicobacter em cães oriundos do Biotério Central da UNESP e, dada a origem desses, a probabilidade da seleção da espécie pylori nesses animais.

\section{Métodos}

Foram utilizados 109 caninos sem raça definida, 49 machos e 60 fêmeas, com peso variando entre 6 e $27 \mathrm{Kg}$. Os animais foram capturados em várias cidades do Estado de São Paulo, e encaminhados ao Biotério Central da UNESP, Campus de Botucatu, sendo submetidos ao protocolo de quarentena antes do estudo. Este estudo foi aprovado pelo CEEA.

Foram utilizados três testes para investigar a presença de Helicobacter sp, sendo um deles específico para espécie Helicobacter pylori: teste imunocromotográfico; teste rápido de urease e análise histológica pela coloração de Giemsa

Todos os animais foram anestesiados antes do procedimento com solução de pentobarbital sódico $3 \%$ na dosagem de $30 \mathrm{mg} / \mathrm{kg} / \mathrm{IV}$, com dose 
suplementar do anestésico, quando necessário.

Foram retirados $10 \mathrm{ml}$ de sangue venoso de cada animal, colocados em tubo de vidro sem anticoagulante, com a finalidade de analisar quantitativamente os anticorpos anti-Helicobacter pylori, por meio do teste sorológico $\mathrm{H}$. pylori-One Step Teste ${ }^{\circledR}$.

As amostras gástricas foram coletadas por endoscopia em 61 animais e por meio da técnica aberta em 48 animais, sendo duas amostras do antro gástrico, duas do fundo gástrico, duas do corpo gástrico e duas do duodeno; após a coleta as biópsias foram imersas em solução tamponada de formaldeído a $10 \%$, para posterior coloração pelo corante de Giensa modificado.

Uma terceira amostra retirada no fundo gástrico era imediatamente colocada em soluçãopadrão de uréia a $10 \%$ e vermelho fenol para realização do teste rápido de urease. Todo procedimento foi realizado com EPI por todos os membros da equipe.

A cada realização do procedimento, em ambas as técnicas, todo o material ficava imerso em solução de glutaraldeído a $10 \%$ por 30 minutos após limpeza mecânica dos mesmos.

\section{Resultados}

Na Tabela 1, estão relacionados os animais distribuídos pelo sexo com positividade para Helicobacter pelo teste da urease, assim como a porcentagem relativa a cada sexo e em relação ao total de animais utilizados.

Na Tabela 2 encontra-se a freqüência de positividade para Helicobacter pela coloração de Giemsa, quando analisada as 4 regiões de obtenção das amostras simultaneamente. A Tabela 3 mostra a freqüência de amostras positivas para Helicobacter por esta técnica em cada uma das regiões examinadas e a Figura 1 ilustra o aspecto das bactérias à microscopia de imersão.

Na Tabela 4 estão distribuídos os animais por sexo com a porcentagem correspondente de positividade para a ocorrência de Helicobacter pylori pela técnica imunocromatográfica, utilizando-se o Kit One Step Teste. As Figuras 2 e 3 ilustram, respectivamente, o teste positivo e negativo para diagnóstico de $H$. pylori por esta técnica.

TABELA 1 - Distribuição dos animais pelo sexo, com positividade para Helicobacter pelo teste rápido da urease e porcentagem correspondente.

\begin{tabular}{lccc}
\hline Sexo & $\mathbf{n}^{\mathbf{0}}$ animais utilizados & $\mathbf{N}^{\mathbf{0}}$ animais positivos & Porcentagem \\
\hline Macho & 49 & 48 & 97,96 \\
Fêmea & 60 & 60 & 100,00 \\
\hline Total geral & 109 & 108 & 99,08 \\
\hline
\end{tabular}

TABELA 2 - Freqüiência relativa da ocorrência de Helicobacter à coloração pelo Giemsa, quando analisada as 4 regiões simultaneamente.

\begin{tabular}{ccc}
\hline $\mathbf{n}^{\mathbf{0}}$ região positiva & $\mathbf{n}^{\mathbf{0}}$ animais & Freqüência relativa \\
\hline 0 & 1 & 0,92 \\
01 & 3 & 2,75 \\
02 & 6 & 5,51 \\
03 & 20 & 18,35 \\
04 & 79 & 72,47 \\
\hline Total & 109 & 100 \\
\hline
\end{tabular}

\footnotetext{
${ }^{\circledR}$ Inlab diagnostica 
TABELA 3 - Freqüência de amostras com coloração positiva para Helicobacter em cada uma das regiões examinadas.

\begin{tabular}{lcccc}
\hline & \multicolumn{4}{c}{ Região } \\
\cline { 2 - 5 } & Antro & Fundo & Corpo & Duodeno \\
\hline Amostras positivas & 94 & 105 & 104 & 88 \\
Porcentagem & 86,23 & 96,33 & 95,41 & 80,73 \\
Limites & $79,77-$ Pos- 92,71 & $92,80-$ Pos - 99,86 & $91,49-$ Pos $-99,34$ & $73,33-$ Pos - 88,14 \\
\hline Total das amostras & 109 & 109 & 109 & 109 \\
\hline
\end{tabular}

TABELA 4 - Distribuição dos animais pelo sexo com positividade para Helicobacter pylori pelo teste imunocromatográfico e porcentagem correspondente.

\begin{tabular}{lccc}
\hline Sexo & $\mathbf{n}^{\circ}$ animais utilizados & $\mathbf{N}^{\mathbf{0}}$ animais positivos & Porcentagem \\
\hline Macho & 49 & 42 & 85,71 \\
Fêmea & 60 & 44 & 73,33 \\
\hline Total geral & 109 & 86 & 78,89 \\
\hline
\end{tabular}
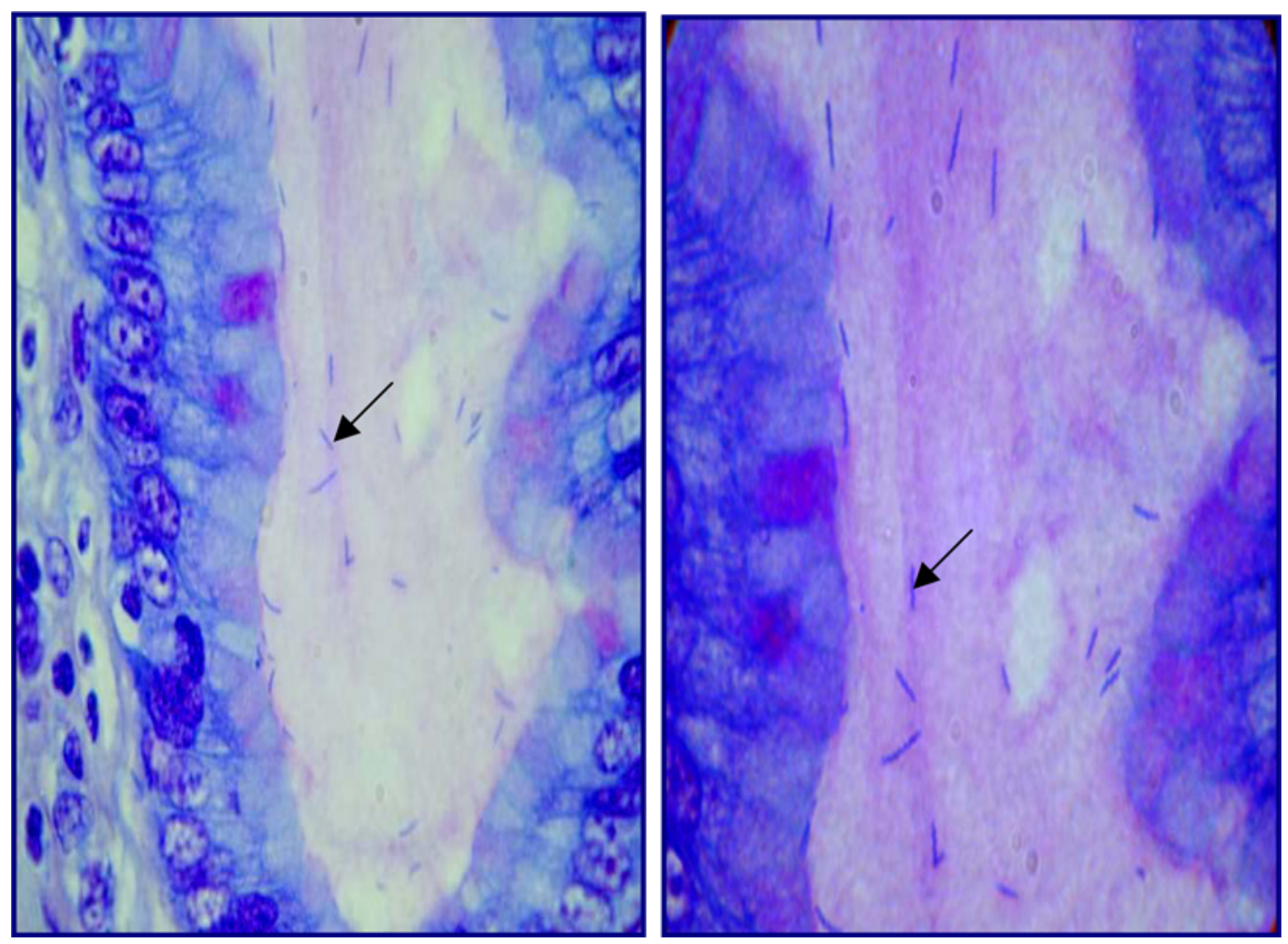

FIGURA 1 - Microscopia de imersão. Bactérias alongadas e espiraladas, tipo “saca-rolhas” nas criptas alveolares visibilizadas pela coloração Giemsa (setas) (aumento 1000X). 


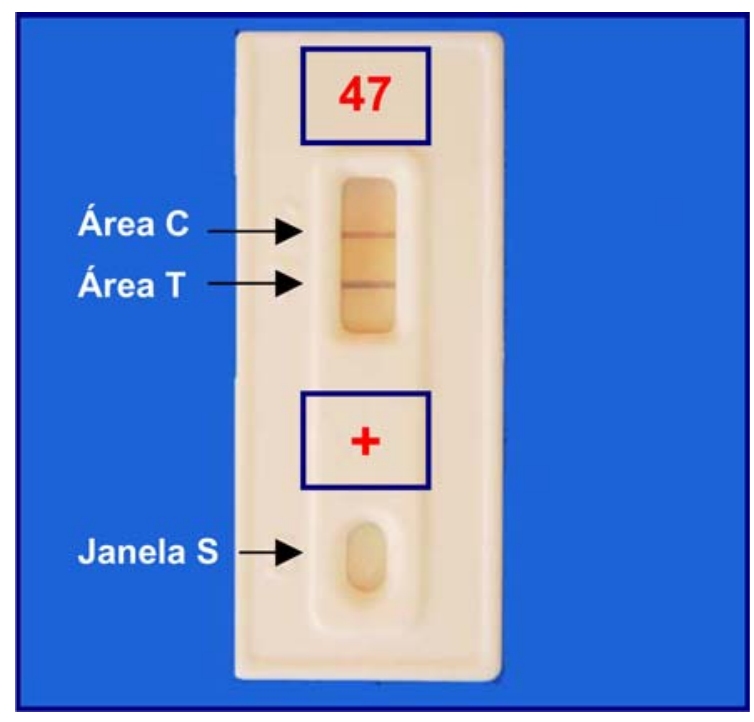

FIGURA 2 - Dispositivo imunocromatográfico com reação positiva para H. pylori no cão 47. A positividade é observada pela faixa rósea na área $\mathrm{T}$ (teste) do dispositivo.

\section{Discussão}

A pesquisa do Helicobacter pode ser realizada por diversos métodos, sendo que pelo menos dois deles devem ser utilizados para avaliar o resultado positivo. Dentre estes métodos, existem os realizados por técnicas invasivas e não invasivas.

Dentre as técnicas invasivas, destaca-se a endoscopia para a obtenção de biopsias gástricas e coleta de sangue para a detecção de antígenos circulantes $^{12}$. Na biopsia gástrica, obtida de pacientes submetidos à endoscopia digestiva alta, vários métodos diagnósticos podem ser utilizados, destacando-se o teste rápido de urease, a cultura, o exame histológico e a reação em cadeia da polimerase (PCR) ${ }^{7}$.

O diagnóstico histológico constitui-se em um método eficaz para diagnóstico do Helicobacter, inclusive com possibilidade em se identificar a espécie envolvida. Como era desconhecida a densidade de bactérias nas amostras gástricas, foi utilizado o método histoquímico de Giemsa modificado que permite a identificação de bactérias quando a densidade de colonização é baixa $^{13}$.

Pelos resultados obtidos, observamos que apenas 1 animal não apresentou a bactéria em nenhuma das 4 regiões examinadas (Tabela 2), sendo que a positividade em pelo menos uma das regiões examinadas estava em 99,08\%,

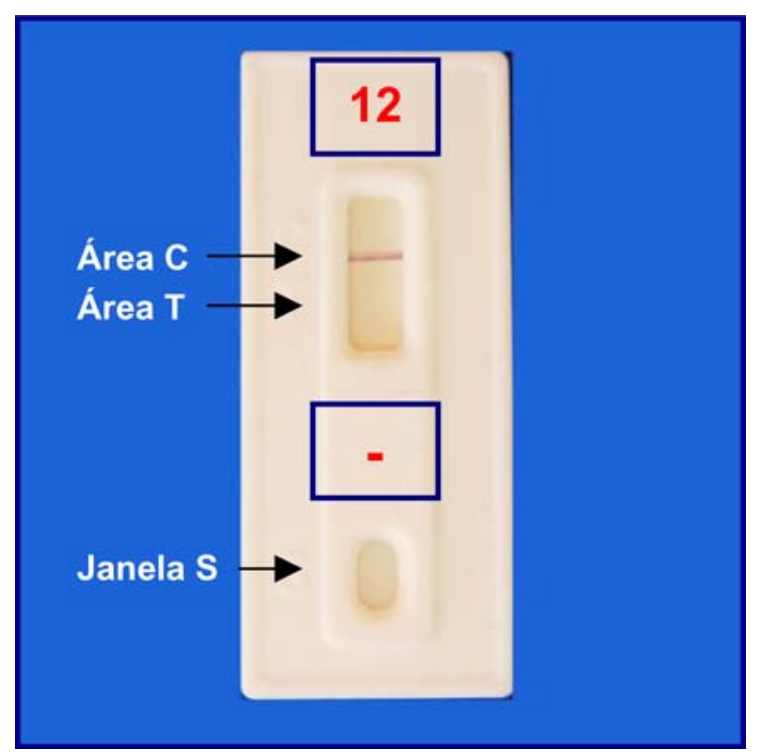

FIGURA 3 - Dispositivo imunocromatográfico com reação negativa para Helicobacter pylori no cão 12. A negatividade é observada pela ausência de coloração na área T (teste) do dispositivo.

correspondendo à 108/109 animais utilizados (Tabela 1). Destaca-se que o acometimento simultâneo das 4 regiões ocorreu em 79 animais, correspondendo à 72,47\% das amostras (Tabela 2). Acrescenta-se aos dados acima que a maior ocorrência de detecção de Helicobacter ocorreu do fundo gástrico, seguido pela ocorrência no corpo gástrico.

A visibilização dessas bactérias ocorreu nas criptas foveolares, distribuídas em grupos, sem invasão das células e com aspecto alongado e aspiralado, tipo “saca-rolha” (Figura 1).

Do mesmo modo, a positividade para Helicobacter pelo teste da urease ocorreu em 99,08\% dos animais. A opção pelo teste deveu-se principalmente ao reduzido tempo de obtenção do resultado (1-12 horas), o baixo custo operacional e a alta sensibilidade do método ${ }^{7}$. Entretanto, resulta-se a impossibilidade em identificar a espécie, já que todas as espécies de Helicobacter que habitam o estômago produzem urease, apresentando portanto, a capacidade de degradar a uréia em amônia, com conseqüente mudança do $\mathrm{pH}$ da solução e mudança da tonalidade do meio de inoculação.

Os resultados obtidos são coincidentes com os relatados na literatura, em que a colonização pelo Helicobacter é elevada, podendo atingir cifras 
de $100 \%{ }^{5,6,7,8,9,10}$. No entanto, não foi documentada a colonização natural pelo Helicobacter pylori.

A análise pelo teste sorológico mostrou que a detecção do $H$. pylori ocorreu em 78,9\% da totalidade dos animais utilizados (Tabela 4), o que consistiria em seleção desta espécie no animal de experimentação oriundo do Biotério Central, fato até então observado em animais experimentalmente infectados pela espécie pylori $^{14}$.

Este resultado encontrado pode ter como causa a alimentação prévia dos animais antes de sua chegada ao Biotério Central, constituídas por alimentos deteriorados, além da possibilidade de convívio com pessoas de baixo padrão sócioeconômico. As condições anteriores poderiam favorecer a seletividade da espécie $H$. pylori nos animais, visto que em seres humanos já foi documentado que as camadas da população de baixo poder aquisitivo estão relacionadas à uma maior incidência de H. pylori ${ }^{3}$.

Por outro lado, a forma da bactéria à microscopia de imersão, constituída por forma alongada e espiralada, não é compatível com a espécie pylori diagnosticada pela sorologia, e sim compatível com a morfologia do $H$. helmanni. Esse cruzamento de reação entre as 2 espécies poderia ocorrer se ambas apresentassem antígenos que pudessem ser comuns às 2 espécies ou na eventualidade da raça canina apresentar uma forma diferente de $H$. pylori daquela encontrada em humanos. Em alguns animais identificamos uma segunda forma de Helicobacter, contudo de morfologia também diferente do $H$. pylori.

A análise pelo teste sorológico da espécie de Helicobacter associada à linfoma MALT em humanos mostrou tratar-se de Helicobacter pylori, mas a análise do RNA confirmou tratar-se de Helicobacter heilmannii nesses pacientes ${ }^{1}$. A análise por Western blot foram negativos em todos os pacientes, comprovando tratar-se de linfoma MALT realmente associado ao $H$. heilmannii. Em contra-prova, a resposta imune antígeno-específica em pacientes infectados por $H$. heilmannii e pacientes-controle infectados por $H$. pylori ocorreu com IgA da subunidade B (62 kilodaltons), sendo esta conhecida e presente no $H$. heilmannii.

Assim, a possibilidade de reação cruzada entre as espécies $H$. helmanni e $H$. pylori pode ter ocorrido nesses animais por nós utilizados, já que o kit $H$. pylori One Step Teste captura anticorpos anti-Helicobacter pylori de todos os isotipos (IgG, IgM, IgA). E sendo a subunidade B de IgA presente e conhecida no $H$. helmanni poderia explicar a positividade elevada para $H$. pylori em nossos animais. $\mathrm{O}$ dispositivo imunocromatográfico contém antígenos imobilizados e um corante que quando capta anticorpos desencadeia a formação de um complexo antígeno-anticorpo-corante, detectado pelo aparecimento de uma faixa rósea na área $\mathrm{T}$ do dispositivo imunocromatográfico. A faixa rósea na área $\mathrm{C}$ do dispositivo indica a validade deste e independe de anticorpos circulante, ocorrendo por uma reação imunoquímica (Figura 2 e 3).

Sendo o cão o hospedeiro primário da espécie $H$. helmanni, em associação ao aspecto histológico das bactérias encontradas, é pouco provável tratarse de $H$. pylori em nossos animais, à despeito da alta positividade apresentada pelo teste sorológico. No entanto, estes animais podem compor uma importante fonte de disseminação desta espécie para a equipe de pesquisadores, já que a infecção do homem por $H$. helmanni também leva à quadros clínicos definidos como a gastrite ${ }^{4}$ e linfoma MALT $^{3}$. Ressalta-se que devido à pequena ocorrência de $H$. helmanni em humanos em relação ao $H$. pylori, a probabilidade de ocorrência do linfoma MALT é maior quando a infecção se faz pelo $H$. helmanni ${ }^{1}$.

A necessidade da confirmação precisa da etiologia da Helicobacteriose identificada no presente estudo remete a um possível aprofundamento da pesquisa a fim de comprovar se há identidade ou não entre a Helicobacteriose encontrada no seres humanos e caninos. Nesse sentido, testes específicos e mais acessíveis dos que os atualmente em uso podem ser desenvolvidos para a verificação da espécie de Helicobacter envolvido tanto em caninos como em seres humanos.

\section{Conclusão}

Frente à metodologia empregada no presente estudo, podemos concluir à respeito dos cães oriundos do Biotério Central da UNESP e utilizados em pesquisas experimentais que: 
1) Estes animais apresentam taxa de colonização por Helicobacter em 99,02\% da amostragem;

2) O aspecto histológico é compatível com a espécie helmanni;

3) A sorologia utilizando o kit $H$. pylori One Step Teste não é específica para a detecção do $H$. pylori;

4) Estes animais não são naturalmente infectados pelo $H$. pylori.

\section{Referências}

1- Morgner A, Lehn N, Andersen LP, Thiede C, Bennedsen M, Trebesius K, Neubauer B, Neubauer A, Stlte M, Bayerdörfer E. Helicobacter heilmannii- associated primary gastric low-grade MALT lymphoma: complete remission after curing the infection. Gastroenterology 2000;118:821-8.

2- Megraud F. Epidemiology of Helicobacter pylori infection. Gastroenterol Clin North Am 1993;22:73-88.

3- Souto FJD, Fontes CJF, Rocha GA, Oliveira AMR., Mendes EN, Queiroz DMMQ. Prevalence of Helicobacter pylori Infection in a rural area of the State of Mato Grosso, Brazil. Mem Inst Oswaldo Cruz 1998; 93:171-4.

4- Rodrigues MAM, Câmara ACB, Figueiredo AAO, Frederigue JU. Gastrite crônica associada a infecção pelo “Gastrospirillum hominis”. Gastroenterol Endoscop Dig 1996;15:141-3.

5- Hermanns W, Kregel K, Breuer W, Lenchner J. Helicobacter-like organisms: histopathological examination of gastric biopsies from dogs and cats. J Comp Pathol 1995;112:307-18.

6- Lecoindre P, Chevallier M, Peyrol S, Boude M, Montclos
H. Contribution à l'étude des hélicobactéries de léstomac du chien et de leur role pathogène. Rev Méd Vet 1995;146:671-80.

7- Eaton KA, Dewhirst FE, Paster BJ, Tzellas N, Coleman BE, Paola J. Prevalence and varieties of Helicobacter species in dogs from random sources and pet dogs: animal and public health implications. J Clin Microbiol 1996;34:3165-70.

8- Happonen I, Linden J, Saari S, Karjalainen M, Häanninen ML, Jalava K. Detection and effects of Helicobacters in healthy dogs and dogs with signs of gastritis. J Am Vet Med Assoc 1998;213:1767-74.

9- Mendes EN, Collares GB, Gonçal.ves HL, Queiroz DMM, Rocha GA, Mesquita Filho PR. Pesquisa de Helicobacter na mucosa gástrica de animais domésticos. In: Resumos do 20o congresso Brasileiro de Microbiologia;1999, Salvador.

10-Hwang CY, Han HR, Youn HY. Prevalence and clinical characterization of gastric Helicobacter species infection of dogs and cats in Korea. J Vet Sci 2002;3:123-34.

11-Simpson KW , Strauss-Ayali D, McDonough PL, Chang YF, Valentine BA. Gastric function in dogs with naturally acquired gastric Helicobacter spp. Infection. J Vet Intern Med 1999a; 13:507-15.

12-Ladeira MSP. Estudos dos danos do DNA de células da mucosa gástrica de pacientes com gastrite crônica, úlcera péptica e câncer gástrico, infectados ou não por $\mathrm{H}$. pylori. [Tese - Doutorado]. Universidade Estadual Paulista-Botucatu; 2001

13-Lechago J. Classificación de lãs gastritis crônicas:después de Houston 94. In: Anais do 23o Congresso Brasileiro de Patologia;1999 Jun 0206; Curitiba.

14-Rossi G, Rossi M, Vitali CG, Fortuna D, Burroni D, Pancotto L et al. A conventional beagle dog model for acute and chronic infection with Helicobacter pylori. Infect Immun 1999;67:3112-20.

Correspondência:

Rogério Saad-Hossne

Faculdade de Medicina de Botucatu-UNESP

Departamento de Cirurgia e Ortopedia

18618-970 Botucatu - SP

saad@fmb.unesp.br

Recebimento: 26/06/2004

Revisão: 18/07/2004

Aprovação: 01/09/2004

Conflito de interesse: nenhum

Fonte de financiamento: nenhuma

\section{Como citar este artigo:}

Souza ML, Kobayasi S, Rodrigues MAM, Saad-Hossne R, Naresse LE. Prevalência de Helicobacter em cães oriundos do biotério central da UNESP-Botucatu. Acta Cir Bras [serial online] 2004 Set-Out;19(5). Disponível em URL: http://www.scielo.br/acb [também em CD-ROM].

*Figuras coloridas disponíveis em www.scielo.br/acb 